\title{
Ladarixin, a dual CXCR1/2 inhibitor, attenuates experimental melanomas harboring different molecular defects by affecting malignant cells and tumor microenvironment
}

\author{
Daria Marley Kemp ${ }^{1}$, Alyson Pidich ${ }^{1}$, Mary Larijani ${ }^{1}$, Rebecca Jonas ${ }^{1}$, Elizabeth

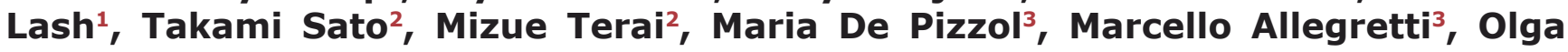 \\ Igoucheva $^{1}$ and Vitali Alexeev ${ }^{1}$ \\ ${ }^{1}$ Department of Dermatology and Cutaneous Biology, Thomas Jefferson University, Philadelphia, PA, USA \\ 2 Department of Medical Oncology, Thomas Jefferson University, Philadelphia, PA, USA \\ 3 Dompé Farmaceutici SpA, Via Campo di Pile, L'Aquila, Italy \\ Correspondence to: Vitali Alexeev, email: vitali.alexeev@jefferson.edu \\ Keywords: CXCR1/2 inhibitor, melanoma, tumor growth inhibition, melanoma apoptosis, tumor microenvironment \\ Received: January 04, 2017 \\ Accepted: January 11, 2017 \\ Published: January 24, 2017
}

\section{ABSTRACT}

CXCR1 and CXCR2 chemokine receptors and their ligands (CXCL1/2/3/7/8) play an important role in tumor progression. Tested to date CXCR1/2 antagonists and chemokine-targeted antibodies were reported to affect malignant cells in vitro and in animal models. Yet, redundancy of chemotactic signals and toxicity hinder further clinical development of these approaches. In this pre-clinical study we investigated the capacity of a novel small molecule dual CXCR1/2 inhibitor, Ladarixin (LDX), to attenuate progression of experimental human melanomas. Our data showed that LDXmediated inhibition of CXCR1/ 2 abrogated motility and induced apoptosis in cultured cutaneous and uveal melanoma cells and xenografts independently of the molecular defects associated with the malignant phenotype. These effects were mediated by the inhibition of AKT and NF-kB signaling pathways. Moreover, systemic treatment of melanoma-bearing mice with LDX also polarized intratumoral macrophages to M1 phenotype, abrogated intratumoral de novo angiogenesis and inhibited melanoma self-renewal. Collectively, these studies outlined the pre-requisites of the successful CXCR1/2 inhibition on malignant cells and demonstrated multifactorial effects of Ladarixin on cutaneous and uveal melanomas, suggesting therapeutic utility of LDX in treatment of various melanoma types.

\section{INTRODUCTION}

Malignant melanoma expresses and secretes various CXC chemokines, including CXCL1, CXCL2, CXCL3 (GRO family chemokines) and CXCL8 (IL-8). These molecules render the tumor microenvironment and facilitate progression and metastatic dissemination of melanomas via autocrine and paracrine activation of CXCR1 and CXCR2 chemokine receptors (reviewed in [1]). Studies on spontaneously immortal mouse melanocytes showed that stable expression of GRO family members enhances colony-forming abilities of the melanocytes, whereas antibody-mediated blocking of these chemokines inhibits experimental melanoma growth [2-4]. Elevated expression of CXCL8 (IL-8) was also associated with the intratumoral endothelial cell chemotaxis, neovascularization and angiogenesis in vitro and in vivo [5]. Up-regulated expression of IL-8 and CXCL1 were also associated with NF-kB transcription factor activity in cultured melanoma cells $[6,7]$. All of these observations reinforce the concept that Gro-family chemokines and CXCL8 (IL-8) act as paracrine and autocrine mediators on melanoma growth and progression. The biological effects of these chemokines are mediated through two G protein-coupled receptors, CXCR1 and CXCR2 [8]. Engagement of these receptors induces intracellular signaling transmitted through heterotrimeric $\mathrm{G}$ proteins with $\mathrm{G} \alpha \mathrm{i}$ being a predominant $\mathrm{G}$ protein coupled to this receptor family [9]. CXCR1 and CXCR2 receptors also exhibit a markedly distinct ligand binding pharmacology: CXCR1 is predominantly activated by 
CXCL8 and CXCL6, whereas CXCR2 could be activated by CXCL1-3 and 5-8 [10]. Expression of both receptors and multiple ligands by melanoma present certain challenges in designing therapeutic strategies to attenuate the effects of these chemokines [11].

To date, several strategies were employed to reduce/inhibit intracellular signaling mediated by CXCR1 and CXCR2 receptors. A number of ligand-blocking antibodies and small molecular weight antagonists of these chemokines, particularly CXCL8, were developed and tested [11]. Although blocking of individual chemokines provided certain benefits in treatment of acute and chronic inflammation [12], this approach may not provide desired outcome in treating neoplasms due to the redundancy of chemotactic signals.

Further search for effective competitive antagonists led to the identification of a number of compounds that can block CXCR1/2 receptor [11]. An advanced development program was originated by Dompé Farmaceutici with Reparixin, the first non-competitive allosteric CXCR1/2 inhibitor that is currently under active clinical investigation for the prevention of graft loss in pancreatic islet transplantation (Phase 3) and treatment of metastatic triple negative breast cancer (Phase 2). Ladarixin (LDX) is a second generation dual CXCR $1 / 2$ inhibitor due to its $>100$ fold higher affinity for the CXCR2 receptor and improved pharmacokinetic properties that make it suitable for oral chronic administration. Ladarixin inhibits human polymorphonuclear leukocyte (PMN) migration to CXCL8 (IC50 at $0.7 \mathrm{nM}$ ) in vitro, and prevents PMN infiltration and tissue damage in several models of IR injury in vivo [13]. LDX is well-tolerated at all studied doses and showed excellent safety profile in human subjects in current clinical trials for the treatment of Type 1 diabetes (unpublished data). In this study, we demonstrated that LDX attenuates progression of different melanoma types in vivo via inhibition of cell cycle progression and motility, blocking of the pro-survival intracellular signals and induction of apoptosis, alteration of the intratumoral recruitment of the endothelial cells and de novo angiogenesis, and hindering of the melanoma selfrenewal mechanisms.

\section{RESULTS}

\section{Analysis of CXCL1/2/3/8 chemokines and CXCR1/2 receptors in primary melanoma cells}

Considering heterogeneity of human melanomas, various molecular defects associated with discrete types of this neoplasm, and variable patterns of chemokine/ receptor expression, we examined several primary human melanoma cell lines characterized by different molecular defects for the expression of CXCR $1 / 2$ and their ligands (CXCL1/8). Cutaneous melanoma cells expressing mutant $\mathrm{BRAF}^{\mathrm{V} 600 \mathrm{E}}(\mathrm{WM} 164, \mathrm{WM} 115, \mathrm{WM} 873)$ [14, 15], cells with non-defined molecular defect expressing BRAF ${ }^{\mathrm{G} 464 \mathrm{E}}$ and $\mathrm{KRAS}^{\mathrm{G12D}}$ (C8161) [16] and uveal melanoma cells harboring an activating mutation in GNAQ ${ }^{\text {2209P }}$ (UM001) [17] were used for this assessment. RT-PCR analysis showed that CXCL1 and CXCL8 were differently expressed in the analyzed cells with the overall lowest expression in WM164 and WM115 and the highest in WM873-1and in C8161 melanoma cells (Figure 1A). Secretion of chemokines from these cells and from primary dark- and light-pigmented primary human melanocytes (1256b and 1603c, respectively) assessed by chemokine antibody array showed that levels of CXCR1/2 ligands were higher in all but one (WM164) melanoma lines as compared to melanocytes (Figure 1B, 1C). Secretion of CXCL8 was consistently elevated in all malignant cells (Figure 1B, 1C). Expression CXCR1/2 receptors was also examined. RT-PCR and Western Blot analyses confirmed expression of both receptors in malignant cells with on average 2 times higher expression of CXCR2 as compared to CXCR1 (Figure 1A). However, FACS analysis demonstrated that CXCR1 and CXCR2 were not uniformly present on the surface of the malignant cells. More than 50\% of WM164 and UM001cells have these receptors consistently present on the cell surface, whereas only small populations of WM873, C8161and WM115 were recognized as receptor-positive (Figure 1D). FACS also revealed the existence of a discrete population of the CXCR1/2 cell surface-positive malignant cells (Figure 1D). These observations were confirmed by the direct (Figure 1E) and indirect (Supplementary Figure S1A) immunofluorescent detection of the receptors showing that WM115 and WM873 cells contained receptor-positive and negative populations, whereas a majority of the WM164 and UM001 were positive for both receptors on the cell surface (Figure 1E, Supplementary Figure S1A).

\section{Ladarixin-mediated inhibition of melanoma motility, adhesion and survival in vitro}

Considering involvement of the CXCR1/2 signaling in migration, the effect of the LDX on motility of melanoma cells was examined using in vitro migration/ scratch assay. The presence of LDX in normal culture media for $24 \mathrm{~h}$ led to an inhibition of melanoma cell motility (Figure 2A, 2B). A more profound inhibition was observed on cells with higher cell surface CXCR1/2 and lower expression of their ligands (WM164, WM115, and UM001 lines). Treatment of these cells with LDX led to 10-fold inhibition of cell migration. Exposure of WM873 and C8161 cells with lower cell surface receptor expression to LDX led to a 2-fold decrease of motility (Figure 2B). 
In these experiments, we observed an increased number of dislodged cells in the presence of LDX. This sparked further assessment of cellular attachment and adhesion by the modified McClay substrata binding assay as described in our prior studies [18]. The presence of the LDX during plating and for additional $4 \mathrm{~h}$ did not alter the adhesion of the LDX-treated and control cells, although a slight reduction in a number of adherent UM001 cells was observed (Table 1). Exposure of melanoma cells to LDX for 3 days affected mostly WM164 cells with 3 times more cells remaining on plastic substrata when cultured in the absence of the LDX. Exposure of cells to LDX for an additional 2 days had a more detrimental effect on all cell lines. On average, 3 times more cells remained attached to plastic substrata when cultured in the absence of LDX (Table 2). These findings suggest that LDX-mediated blocking of the CXCR $1 / 2$ signaling affects expression of the adhesion molecules or leads to the cell death and detachment. Therefore, expression of cadherins was analyzed by Western blot under referenced above conditions. High expression of epithelial cadherin (E-cadherin) was detected only in WM35 melanoma cells isolated from primary (radial growth phase) lesion. In cells from more advanced lesions (vertical growth phase or metastatic), a substantial reduction or absence of this cadherin was observed (Figure 2C). N-Cadherin, which is commonly associated with invasion and metastasis of neoplasms, was detected in all cell lines isolated from local and distal metastatic lesions with the lowest expression in the WM35 cell line. P-cadherin, whose expression is associated with poorly differentiated carcinomas [19, 20], was barely detectable in all examined cells. Treatment of cells with LDX did not alter expression of these cadherins (Figure 2C), suggesting that progressive loss of attached LDX-treated cells could be attributed to apoptosis. Based on the in situ cell death detection (TUNEL) assay, on average, about $3 \%$ of all control cells were identified as apoptotic whereas LDX treatment increased apoptosis up to $10 \%$ for C8161 and WM873 cells, $25 \%$ for WM 164 and WM115 cells, and up to 40\% for UM001 (Figure 2D, 2E).

Given that NF-kB supports survival of the malignant cells via $\mathrm{Bcl}-2 / \mathrm{Bcl}-\mathrm{XL}-d e p e n d e n t$ pathway and augments transcription of CXCR1/2 ligands [1], we investigated whether LDX treatment abrogates NF-kB expression and/or activation. To assess whether LDXmediated CXCR1/2 blocking affects NF-kB activity, we generated several melanoma cell lines stably expressing NanoLuc $^{\circledR}$ luciferase under the control of the NF- $\kappa B$ response elements. Exposure of these cells to LDX (1 $\eta \mathrm{M}, 100 \eta \mathrm{M}, 1 \mu \mathrm{M})$ for $24 \mathrm{~h}$ in vitro led to reduction of NanoLuc in all examined cells confirming LDX-mediated down-modulation of the NF-kB activity (Supplementary Figure S1B). Exposure of all malignant cells to LDX for $72 \mathrm{~h}$ led to an intracellular re-distribution of NF-kB and its accumulation in the cytoplasm. It was particularly evident in WM164 and UM001 cells (Figure 2F). Western Blot analysis with serine ${ }^{536}$-phosphorylated NF-kBspecific antibodies confirmed the reduction of the NF-kB activation and nuclear translocation in LDX-treated cells. It was most prominent in WM35, WM164, WM115, and UM001, and less pronounced in C8161 cells (Figure 2C). As Akt plays an important role in controlling the balance between survival, apoptosis and NF-kB activation [21], we also assessed the status of this serine-threonine kinase. Based on the Western Blotting, treatment of the cells with LDX did not alter the expression of the AKT but markedly reduced its phosphorylation on Thr308 in all examined cell lines (Figure 2C). Persistent activation of STAT3 has been shown to mediate several oncogenic features in many types of cancers, including melanoma [22]. CXCL8 (IL-8) signaling has been implicated in STAT3 activation and nuclear translocation [23], suggesting that inhibition of CXCR1/2 may also lead to the inhibition of STAT3 in melanoma cells. However, Western Blot analysis showed a relatively low basal level of STAT3 expression in all malignant cells and insignificant changes in STAT3 phosphorylation after LDX treatment (Figure 2C).

Collectively, these in vitro studies demonstrated that exposure of malignant cells to LDX resulted in down- modulation of cell cycle progression, motility, Akt and NF-kB phosphorylation-dependent activation, and induction of apoptosis independently of molecular defects underlying tumorigenic phenotype. These studies also demonstrated that LDX-mediated inhibition of CXCR $1 / 2$ has the most profound effect on melanoma cells with higher level of cell-surface receptors and lower secretion of ligands (eg. WM164), and only partial effect on cells with lower number of cell surface receptors and higher secretion of ligands (eg. C8161).

\section{Ladarixin-mediated inhibition of melanoma xenografts in vivo}

To evaluate the extent of LDX-mediated melanoma inhibition in vivo and better define the underlying molecular mechanisms, 4 different human melanoma cell lines characterized by various levels of cell surface CXCR1/2, ligands secretion and distinct molecular defects (WM164 ${ }^{\mathrm{V} 600 \mathrm{E}}, \mathrm{C} 8161, \mathrm{UM} 001^{\mathrm{Q} 209 \mathrm{P}}$ and UM004 ${ }^{\mathrm{Q} 209 \mathrm{~L}}$ ) were inoculated into nude athymic mice. Starting from day 10 after inoculation, when lesions reached about $50 \mathrm{~mm}^{3}$ ( $\sim 4 \times 4 \times 3 m)$, experimental groups ( $n=10$ per group) were receiving LDX via intraperitoneal (IP) injection once a day at $15 \mathrm{mg} / \mathrm{kg}$. Control animals were receiving saline. Consistent with our in vitro studies, systemic administration of LDX had limited effect on growth of C8161 melanoma lesions but significantly inhibited growth of WM164, UM001 and UM004 melanomas (Figure 3A). All LDX-treated lesions were visually less vascularized (particularly UM001) compared to untreated 
controls (Figure 3A).

Histological examination showed that all lesions from LDX-treated animals contained apoptotic regions with elevated leukocytic infiltrate (Figure 3B). The largest apoptotic regions occupying on average $2 / 3$ of the entire tumor volume were detected in LDX-treated C8161 lesions. These regions were characterized by the presence of TUNEL-positive melanoma cells and a large number

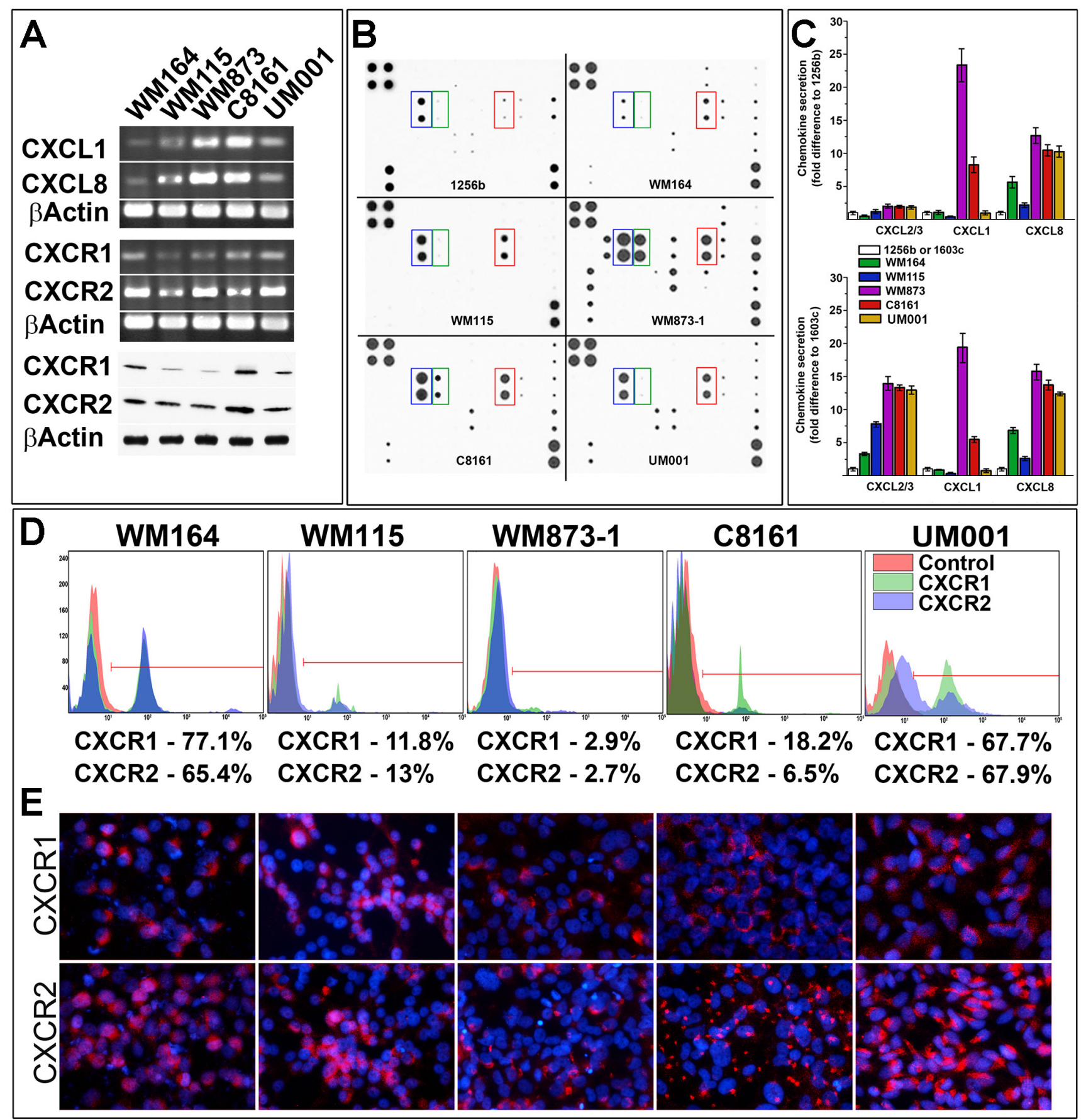

Figure 1: Analysis of chemokines and receptors in primary melanoma cells. A. RT-PCR and Western Blot analyses of CXCL1/8 chemokines and CXCR1/2 receptors expression in different melanoma cell lines (as indicated on the panel). B. Representative images of the antibody array analysis used for the detection of the secreted chemokine. Blue frame - CXCL1/2/3 (Gro family) chemokines; Green frame - CXCL1; Red frame - CXCL8. C. Quantitation of chemokines secretion by melanoma cells relative to light-pigmented (1603c) and dark-pigmented (1256b) melanocytes. Data collected from 3 independent measurements and presented as a fold difference \pm SD. Cell lines are indicated on the panel. D. Analysis of cell-surface CXCR1/2 in melanoma cells by FACS. Cell lines and receptors are indicated on the histograms. Calculated percentage of receptor-positive cells indicated below the histograms. E. Detection of CXCR $1 / 2$ receptors by fluorescently-labeled receptor-specific antibodies. Red - CXCR1/2 receptors, Blue - DAPI nuclear staining. 
of $\mathrm{CD}_{11 \mathrm{~b}^{+}}$leukocytes (Figure 3C, 3D). Considering a dual role of the tumor-infiltrating $\mathrm{CD} 11 \mathrm{~b}^{+}$macrophages that may prevent (M1 macrophages) or promote (M2 macrophages) tumorigenesis [24], expression of nitric oxide synthase 2 (iNOS) as a marker for the M1 macrophages was analyzed. Majority of the intratumoral $\mathrm{CD}_{11} \mathrm{~b}^{+}$cells in control lesions did not express iNOS (Figure 3C, 3D). On the contrary, more than $60 \%$ of

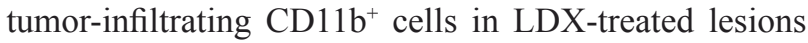
were iNOS-positive (Figure 3C, 3D).

Considering apoptosis as a primary mechanism involved in LDX-mediated melanoma cell death, we examined the status of the key apoptotic markers in LDX-treated and control lesions. Concurrent detection of caspase-cleaved PARP and cytokeratin 18 confirmed apoptotic mechanism of malignant cell death in all LDXtreated animals (Figure 3C, 3D). Quantitation of apoptotic cells showed that more than $60 \%$ of cells in the affected regions were positive for both apoptotic markers. A substantial reduction of the proliferating $\mathrm{Ki}-67^{+}$cells and increased number of the cleaved cytokeratin $18(\mathrm{M} 30+)$ cells were also observed in non-apoptotic regions (Figure $3 \mathrm{C})$. Inverse correlation between $\mathrm{Ki}-67^{+}$proliferating and $\mathrm{M} 30^{+}$apoptotic cell was most distinct in WM164 treated melanomas (Figure 3C, 3D). Immunofluorescent detection of $\mathrm{Ki}-67$ and gp-100 melanoma differentiation antigen confirmed LDX-mediated inhibition of proliferation in malignant cell in non-apoptotic tumor regions (Figure 3C).
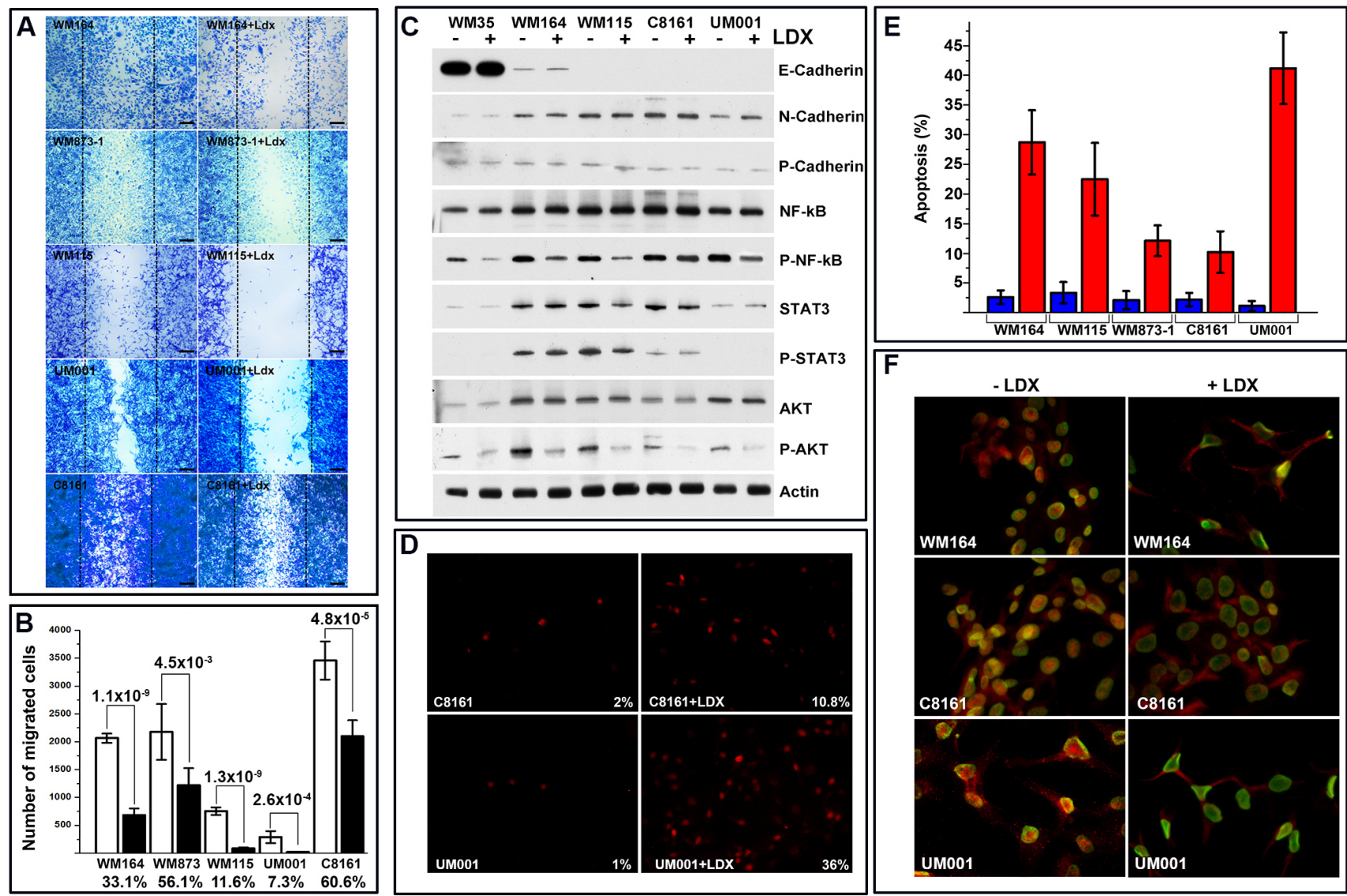

Figure 2: Analysis of melanoma cell motility and apoptosis. A. Micrographs illustrating LDX-mediated inhibition of melanoma cell motility assessed by scratch assay. Cell lines and conditions indicated on the micrographs. Scale bar - 100 mm. Introduced scratches are outlined by puncture lines. B. Quantitation of LDX treated and control melanoma cell migration. Data is presented as an average number of cells migrated into the scratch (10 independent microscopic fields) \pm SD. Statistical significance (p-value) was calculated using 2 tailed $t$-test is shown above the columns. Percentage of migrated LDX-treated cells relative to mock-treated control is shown below the columns. C. Western blot analysis of adhesion and signaling molecules in representative LDX-treated and control melanoma cells (indicated above the panels). Analyzed molecules are shown to the right of the panels. Phosphorylated NF-kB, STAT3 and AKT are marked as P-proteins. Beta actin was used as loading control. D. Microscopic analysis of apoptosis in control and LDX-treated melanoma cells by TUNEL assay. Cell lines, treatment and calculated percentage of apoptotic cells shown on representative images. E. Quantitation of apoptosis as determined by the TUNEL assay in all investigated melanoma cell lines (indicated below the columns). Data is presented as average of 3 independent experiments \pm SD. Five random microscopic fields were used for each treatment condition/cell line to calculate percentage. F. Indirect immunofluorescent analyses of NF-kB nuclear translocation/activation in control and LDX-treated representative melanoma cells. Treatment and cell lines are indicated on the panels. Red - Nf-kB, Green - LaminA/C (outlines nuclear membrane). 
To better define molecular mechanisms involved in LDX-mediated inhibition of melanoma in vivo, NF-kB and STAT3 in control and LDX-treated lesions were examined by the indirect immunofluorescence. This analysis demonstrated preferential nuclear localization of NF-kB in the control and cytoplasmic localization in treated lesions
(Figure 4A). Detection of STAT3 in control and LDXtreated lesions did not reveal any significant differences, although a more pronounced nuclear staining of the STAT3 was detected in controls. These observations were further confirmed by Western blot analysis. A reduction of the Ser ${ }^{536}$-phosphorylated NF-kB and Thr ${ }^{308}$-phosphorylated
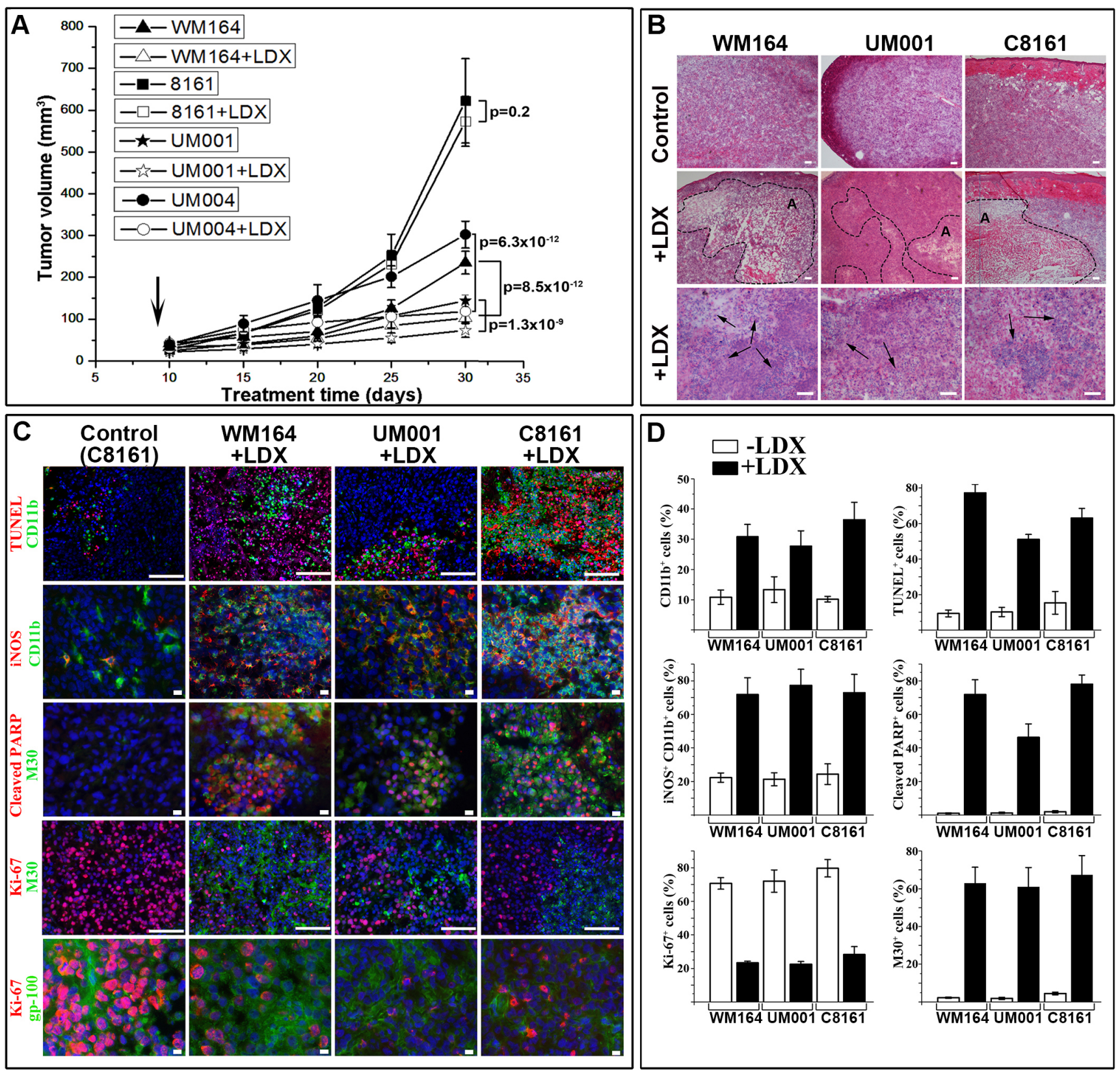

Figure 3: LDX-mediated inhibition of melanoma xenotransplants in vivo. A. Graph of the lesions at 30 days showing tumor development in LDX-treated and control mice. Data is presented as a mean tumor volume $\left(\mathrm{mm}^{3}\right) \pm \mathrm{SD}$. Statistical significance is presented as p-value (shown of the graph). B. Representative micrographs of the H\&E stained sections of the control and LDX treated lesions showing the presence of the apoptotic regions (dotted line) and leukocytic infiltrates (black arrows). C. Indirect immunofluorescence-based characterization of LDX-treated and control tumors. As all mock-treated lesions were similar, micrographs of the control C8161 lesions are shown as representative controls. Detected antigens are shown to the left of the panels in corresponding colors. Blue - DAPI nuclear staining. Scale bars: $10 \mu \mathrm{m}\left(2,3\right.$, and $5^{\text {th }}$ rows from the top $)$ and $100 \mu \mathrm{m}\left(1,4^{\text {th }}\right.$ rows from the top $)$. D. Quantitation of antigen-positive cells shown on panel C. Data is presented as an average percentage of positive cells per microscopic field \pm SD. 
Table 1: Melanoma cell adhesion at plating

\begin{tabular}{|l|c|c|c|c|}
\hline \multicolumn{1}{|c|}{ Ladarixin } & WM164 & C8161 & TSUM1 & Time \\
\hline Ldx- & $0.366 \pm 0.085$ & $0.641 \pm 0.073$ & $0.126 \pm 0.034$ & $4 \mathrm{hr}$ \\
\hline $\mathrm{Ldx}+$ & $0.288 \pm 0.058$ & $0.518 \pm 0.063$ & $0.144 \pm 0.038$ & $4 \mathrm{hr}$ \\
\hline $\mathrm{Ldx}-$ & $0.349 \pm 0.064$ & $0.521 \pm 0.0532$ & $0.394 \pm 0.048$ & $3 \mathrm{hr}$ \\
\hline $\mathrm{Ldx}+$ & $0.221 \pm 0.074$ & $0.435 \pm 0.034$ & $0.313 \pm 0.058$ & $3 \mathrm{hr}$ \\
\hline $\mathrm{Ldx}-$ & $0.310 \pm 0.053$ & $0.524 \pm 0.041$ & $0.338 \pm 0.069$ & $2 \mathrm{hr}$ \\
\hline $\mathrm{Ldx}+$ & $0.221 \pm 0.051$ & $0.483 \pm 0.049$ & $0.322 \pm 0.055$ & $2 \mathrm{hr}$ \\
\hline $\mathrm{Ldx}-$ & $0.333 \pm 0.069$ & $0.519 \pm 0.061$ & $0.346 \pm 0.066$ & $1 \mathrm{hr}$ \\
\hline $\mathrm{Ldx}+$ & $0.219 \pm 0.054$ & $0.418 \pm 0.044$ & $0.301 \pm 0.034$ & $1 \mathrm{hr}$ \\
\hline
\end{tabular}

Data is presented as optical density measured at $570 \mathrm{~nm}\left(\mathrm{OD} \mathrm{A}_{570}\right)$ reflecting attached cells.

Table 2: Assessment of cellular attachment to the plastic substrata (ODA 570$)$

\begin{tabular}{|c|c|c|c|c|}
\hline Time & Ladarixin & WM164 & C8161 & TSUM1 \\
\hline 5 Days & LDX - & $0.178 \pm 0.02$ & $0.175 \pm 0.012$ & $0.156 \pm 0.012$ \\
\hline 5 Days & LDX + & $0.048 \pm 0.017$ & $0.049 \pm 0.011$ & $0.066 \pm 0.013$ \\
\hline 4 Days & LDX - & $0.192 \pm 0.014$ & $0.17 \pm 0.014$ & $0.155 \pm 0.012$ \\
\hline 4 Days & LDX+ & $0.05 \pm 0.013$ & $0.074 \pm 0.017$ & $0.081 \pm 0.017$ \\
\hline 3 Days & LDX - & $0.199 \pm 0.018$ & $0.17 \pm 0.012$ & $0.182 \pm 0.013$ \\
\hline 3 Days & LDX + & $0.059 \pm 0.012$ & $0.185 \pm 0.012$ & $0.157 \pm 0.015$ \\
\hline
\end{tabular}

Data is presented as optical density measured at $570 \mathrm{~nm}\left(\mathrm{OD} \mathrm{A}_{570}\right)$ reflecting density of the attached cells.

AKT and Tyr $^{705}$-phosphorylated STAT3 was observed in all LDX-treated lesions (Figure 4B), suggesting that LDXmediated CXCR1/2 inhibition attenuates NF-kB/AKT activation making malignant cells susceptible to apoptosis and reducing their proliferative capacities.

Previous studies demonstrated that CXCR $1 / 2$ receptors are expressed by microvascular endothelial cells and that secretion of CXCR $1 / 2$ ligands by melanoma enhances de novo angiogenesis [25]. Indirect immunofluorescent detection of the $\mathrm{CD} 31^{+}$intratumoral blood vasculature demonstrated a drastic reduction of endothelial cell recruitment and formation of the intratumoral blood vessels in all examined LDX-treated lesions. Lack of the intratumoral angiogenesis was particularly evident in peri-apoptotic regions of the LDXtreated tumors, where blood vessels were not detected at all (not shown). A reduction $\mathrm{CD} 31^{+}$blood vessels in non-apoptotic regions of all LDX-treated lesions was apparent (Figure 4A) and confirmed by the assessment of microvessel density (Table 3).

Several recent studies suggested that so called tumor-initiating cells responsible for melanoma selfrenewal display high aldehyde dehydrogenase (ALDH) activity and enhanced tumorigenicity over ALDH-negative cells $[26,27]$. Considering a potential correlation between CXCR1/2 expression and ALDH activity reported in breast carcinoma [28, 29], we tested how LDX treatment affects $\mathrm{ALDH}^{+}$melanoma cells. In all cultured cells, independently of the tumorigenic mutation, about $4 \%$ of cells were ALDH-positive whereas in xenotransplants it was increased up to $10 \%$ in the lesions (Figure 5A, 5B). Treatment of tumor-bearing mice with LDX led to an inhibition of ALDH expression in non-apoptotic regions of the lesions where $\mathrm{ALDH}^{+}, \mathrm{HMB}^{+}\left(\mathrm{gp} 100^{+}\right)$malignant cells were rarely detected (Figure 5A, 5B, 5C). Percentage of these cells decreased on average 4 times for UM001, 8 times for WM164, and 10 times for C8161 (Figure 5C). Concurrently, a higher percentage of the $\mathrm{ALDH}^{+}$cells was detected in non-proliferating, apoptotic, ${\mathrm{M} 30^{+}}^{+}$regions of LDX treated lesions (Figure 5B, 5C). In fact, all $\mathrm{ALDH}^{+}$ cells were also positive for caspase-cleaved cytokeratin 18 (Figure 5B). Collectively, these data demonstrated that treatment of melanoma-bearing mice with LDX leads to the inhibition of ALDH in non-apoptotic malignant cells and its induction in cells undergoing apoptosis.

\section{DISCUSSION}

Previous studies demonstrated that different CXCR1 and CXCR2 antagonists can block these receptors inhibiting inflammation and tumor growth in various animal models. For example, G31P, an IL-8 analog, was shown to block neutrophil infiltration, pyrexia, and pulmonary vascular pathology in endotoxemic animals 
[30, 31]. SCH-527123 and SCH-479833, dual CXCR1/2 and CXCR2 antagonists, were shown to inhibit migration and proliferation of A375SM melanoma cells [32]. SCH527123 was described as a potent inhibitor of CXCR1$(\mathrm{IC} 50=41 \mathrm{nM})$ and CXCR2 $($ IC50 $=3 \mathrm{nM})$ mediated chemotaxis with high affinity [33]. It was shown to inhibit neutrophil recruitment, mucus production and goblet cell hyperplasia in animal models of pulmonary inflammation [34]. The potential therapeutic effect of $\mathrm{SCH}-527123$ in the treatment of chronic pulmonary diseases has been widely investigated in several clinical studies, but the lack of evident long-term clinical benefit and associated neutropenia led to discontinuation of its clinical development [35-37]. In this study, we assessed therapeutic aspects of a novel, dual small molecule CXCR1/2 inhibitor, Ladarixin, to attenuate development and progression of human melanomas characterized by different molecular defects. Ladarixin is orally bioavailable, potent and selective non-competitive allosteric CXCR $1 / 2$ inhibitor that binds an allosteric pocket of the trans-membrane region of both receptors. The allosteric action results in a dramatic reduction of CXCR1 $($ IC50 $=0.9 \mathrm{nM})$ and CXCR2 $($ IC50 $=0.8 \mathrm{nM})$ mediated chemotaxis in the absence of any significant influence on ligand/receptor binding [38]. Ladarixin was also effective in decreasing CXCL8-induced
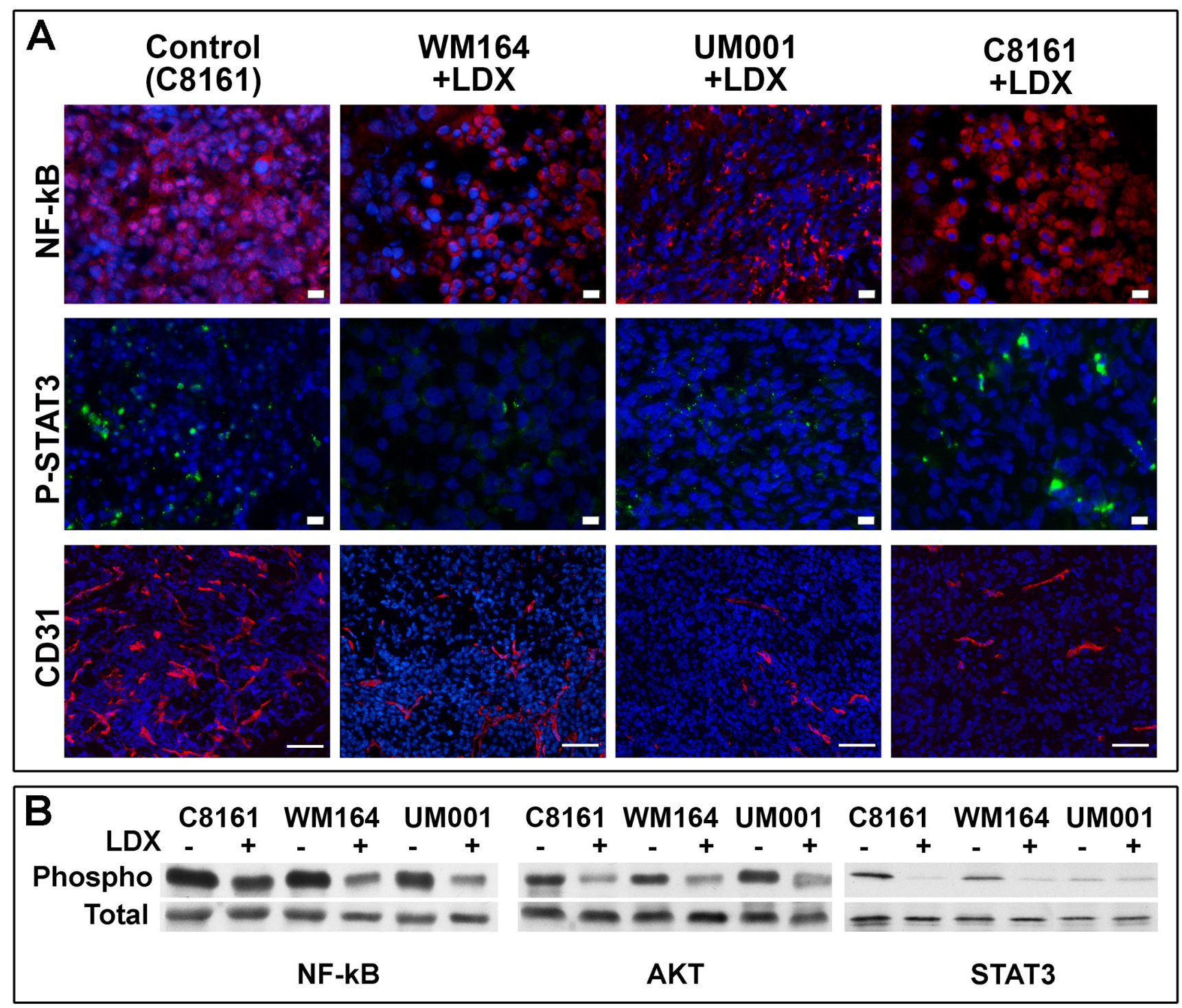

Figure 4: Analysis of NF-kB, STAT3, AKT and angiogenesis in control and LDX-treated lesions. A. Indirect immunofluorescent analysis of NF-kB, STAT3 and CD31 (as a marker of angiogenesis de novo) in control and LDX-treated lesions. As all mock-treated lesions were similar, micrographs of the control C8161 lesions are shown as representative controls. Detected antigens (in corresponding colors) are show to the left of the panels. Blue - DAPI nuclear staining. Cell lines and treatments are shown above the panels. Scale bar - $10 \mu \mathrm{m}$. B. Western blot analysis of NF-kB, STAT3, AKT phosphorylation in control and LDX-treated lesions. Cell lines and treatments are shown above the panels. 
polymorphonuclear leukocyte infiltration in several animal models without a significant dose-related reduction in systemic neutrophil counts. Confirmation of this last observation from Phase 1 clinical studies suggests that allosteric modulation may represent a promising approach to the design of safe and well-tolerated drugs acting at chemokine receptors.

Limited number of reports on targeted inhibition of Gro family chemokines, CXCL8 (IL-8) and their receptors (CXCR1 and CXCR2) in various tumor models including melanomas, suggested a potential applicability of these approaches for tumor growth inhibition (11). However, redundancy of chemotactic signals presents a significant challenge in designing therapeutic strategies to attenuate the effects of CXCR1/2 signaling on melanoma cells and tumor microenvironments, and the pre-requisites for the successful treatment remain undefined. Presented here analysis demonstrated that melanoma cells secrete different levels CXCL1 and CXCL8 and rather high levels of CXCL2 and CXCL3 chemokines (Figure 1). Concurrently, tumor cells express both $\mathrm{CXCR} 1 / 2$ receptors. FACS analysis revealed the existence of

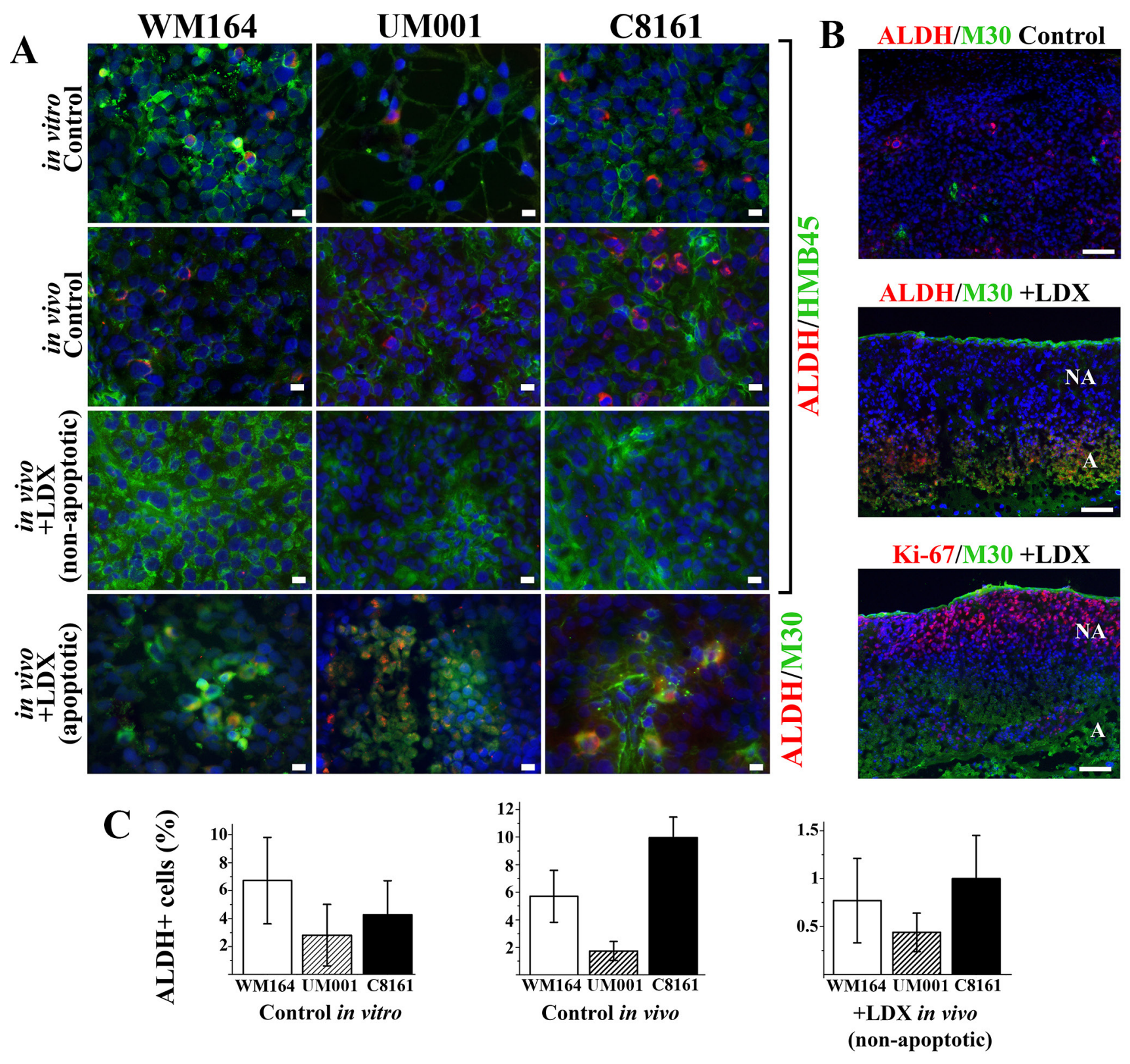

Figure 5: Assessment of tumor-initiating ALDH ${ }^{+}$melanoma cells in vitro and in vivo. A. Indirect immunofluorescent detection of ALDH+ melanoma cells in vitro and in vivo. Detected antigens (in corresponding colors) are shown to the right of the panels. Scale bar - $10 \mu \mathrm{m}$. B. Indirect immunofluorescent detection of the $\mathrm{ALDH}^{+}$cells in non-proliferating (Ki-67-negative), apoptotic (M30-positive) cells in LDX-treated lesions. Scale bar - $100 \mu \mathrm{m}$. C. Quantitation of $\mathrm{ALDH}^{+}$cells in control cultured cells and non-apoptotic regions of the LDX-treated lesions (Panel A). Data is presented as average percentage of $\mathrm{ALDH}^{+}$cells per microscopic field $\pm \mathrm{SD}$. 
Table 3: LDX-mediated inhibition intratumoral microvessel density (MVD)

\begin{tabular}{|c|c|c|c|}
\hline Cells & MVD ( \pm SD) $-/ /+$ LDX & \% inhibition & $\boldsymbol{t}$-test \\
\hline C8161 & $22 \pm 4 / / 8 \pm 3$ & 62 & $<0.05$ \\
\hline WM164 & $18 \pm 4 / / 4 \pm 2$ & 78 & $<0.05$ \\
\hline UM001 & $15 \pm 2 / / 4 \pm 2$ & 73 & $<0.05$ \\
\hline UM004 & $14 \pm 2 / / 5 \pm 2$ & 65 & $<0.05$ \\
\hline
\end{tabular}

Immunofluorescent staining for microvessel using anti-CD31 was analyzed as described in Materials and Methods. MVD was quantitated on 10 independent microscopic fields per sample.

distinct populations of receptor-positive and receptornegative cells in otherwise homogeneous malignant cell cultures (Figure 1D). This analysis also demonstrated that despite a rather high level of CXCR1/2 expression in some melanoma cells (eg. WM873 and C8161), only a small percentage of cells had receptors on the cell surface, whereas other cells (eg. WM164 and UM001) had a consistently high number of receptor-positive cells. These observations suggest that in malignant cells with high secretion of the autocrine chemokines and high level of CXCR1/2 expression (as in WM873 and C8161) a rapid binding and internalization of the ligand/receptor complexes may lead to the "removal" of the receptors from the cell surface, as previously observed for CXCR4CXCL12 [39]. These findings also suggest that CXCR1/2 blocking may have limited direct effect on melanoma cells with the lower number of cell surface receptors and high levels of autocrine chemokines.

Consistent with the prior data obtained on A375SM cells using SCH-527123 inhibitor (29), LDX treatment inhibited melanoma cells motility. However, our analysis clearly demonstrated that LDX-mediated inhibition of motility, proliferation, AKT and NF-kB activation and induction of apoptosis directly correlated with the percentage of CXCR1/2-positive cells. Thus, WM164, WM115 and UM001 cells were more susceptible to the LDX treatment than WM873 or C6181 cell. Importantly, treatment of different melanoma cells in vitro with $1 \mu \mathrm{M}$ LDX was more effective than treatment of A37SM with $250 \mu \mathrm{M} \mathrm{SCH}-527123$ (29).

Consistent with the in vitro data, treatment of the experimental melanoma-bearing mice with LDX $(15 \mathrm{mg} /$ $\mathrm{kg}$ ) led to the inhibition of tumor growth independently of the molecular defects underlying tumorigenic phenotype. Thus, statistically significant inhibition of BRAFV600E WM164, GNA11 ${ }^{\text {209L }} \mathrm{UM} 001$ and GNAQQ209P UM004 melanomas was observed (Figure 3). These observations support the notion that malignant cells with higher cellsurface CXCR $1 / 2$ expression and lower expression the ligands (e.g. WM164) are more susceptible to LDX than cells with lower sell surface receptors (e.g. C8161). Although, treatment of C8161 melanoma-bearing mice with LDX did not alter outgrowth of the intradermal tumors, normalized rate of apoptosis and inhibition of proliferation were similar in all LDX-treated lesions (Figure 3D) and C8161 lesions contained large apoptotic regions approaching $2 / 3$ of the entire tumor volume. Such discrepancy could be explained by faster proliferation of the C8161 cells, higher expression of the CXCR1/2 ligands that cause rapid internalization of the receptors and higher microvascular density, particularly, in the periphery of the established C8161 tumors. Together with the inhibition of AKT and NF-KB activation/phosphorylation in vitro (Figure 2) and in vivo (Figure 4A), our data indicate that LDX-mediated induction of apoptosis in malignant cells is associated with down-modulation of the AKT/NF-kBmediated pro-survival signals. Comparison of our in vivo data with previous findings obtained using $\mathrm{SCH}-527123$ at $100 \mathrm{mg} / \mathrm{kg}$ dose [32] showed that systemic treatment of tumor-bearing mice with LDX is more effective, as reflected by the inhibition of melanoma cell proliferation, angiogenesis and induction of apoptosis (Figure 3D, Figure 4).

Moreover, we observed that apoptotic regions in LDX-treated lesions were heavily infiltrated with CD11 $\mathrm{b}^{+}$ TAMs characterized by the uniform expression of the iNOS, a well-known maker of the M1 macrophages with tumoricidal activity. These findings suggest that LDX treatment may directly or indirectly affect polarization of the TAMs contributing further to the inhibition of the neoplasms.

Previous studies demonstrated that CXCR $1 / 2$ expressed on the surface of the blood endothelial cells play an important role in the recruitment and the intratumoral de novo angiogenesis $[5,25]$. Our analysis demonstrated a significant reduction of the intratumoral $\mathrm{CD} 31^{+}$endothelial cells and blood vessels in LDX-treated tumor-bearing mice (Figure 4). These findings also indicate that LDX-mediated alteration of the melanoma-supporting microenvironment additionally attenuates tumor progression and may further contribute to the induction of apoptosis of the malignant cells (eg. C8161).

Presented here studies also support the notion that LDX treatment prevents "rejuvenation' of the tumors by affecting cells with enhanced tumorigenic capabilities, so called melanoma-initiating cells. Several recent studies demonstrated that a distinct population of human melanoma cells with high ALDH activity is responsible for tumorigenesis and tumor self-renewal $[26,27]$ and that silencing of ALDH by shRNA leads to melanoma cell cycle arrest, apoptosis, decreased cell viability in vitro and reduced tumorigenesis in vivo [27]. Therefore, a decrease of the $\mathrm{ALDH}^{+}$melanoma cells in non-apoptotic regions of all LDX-treated tumors (Figure 5) could 
be directly related to the reduced tumor-regenerating capacity and abrogation of melanoma self-renewal mechanism. Although we identified a higher percentage of the $\mathrm{ALDH}^{+}$cells in the apoptotic regions, ALDH expression coincided with the caspase-mediated cleavage and release of the cytokeratin 18 fragments (Figure 5), the hallmark of the intermediate stage of apoptosis. Apoptosis is a tightly regulated process that inevitably leads to structural and biochemical changes and eventually to cell death and phagocytosis. Although, ALDH is an enzyme that detoxifies aldehydic products generated by reactive oxygen species and enhances cell survival, it is unlikely that ALDH expression in apoptotic cells may reverse mid-apoptosis. This notion is indirectly supported by the accumulation of the macrophages in apoptotic regions that phagocytose dead melanoma cells.

Collectively, presented here data demonstrate that Ladarixin, a dual CXCR1/2 small molecule inhibitor, has a multifactorial effect on melanomas in vitro and in vivo independently of the genetic defects underlying tumorigenic phenotype. These effects include inhibition of melanoma cell motility, NF-kB and AKT-mediated prosurvival signaling, increased apoptosis, down-modulation of pro-angiogenic signaling and formation of the intratumoral microvasculature de novo, polarization of the intratumoral macrophages to M1 tumoricidal phenotype, and blocking of the $\mathrm{ALDH}^{+}$cell-dependent melanoma self-renewal mechanism. These pre-clinical findings demonstrated therapeutic utility of LDX for the inhibition of various melanomas independently of the tumor-driving mutations.

\section{MATERIALS AND METHODS}

\section{Cell lines and culture}

All WM and C8161 primary melanoma cell lines were kindly provided by Dr. M.Herlin (Wistar Institute, Philadelphia PA). Cell were cultured in MCDB164/L15 media (4/1) supplemented with 2\% Fetal Bovine Serum (FBS), Bovine insulin, and calcium chloride. Uveal melanoma lines UM001 and UM004 characterized by the activating mutations in GNAQ ${ }^{\text {209P }}$ and GNA11 ${ }^{\mathrm{Q} 209 \mathrm{~L}}$ were provided by Dr. T. Sato (Thomas Jefferson University, Philadelphia PA) and cultured in RPMI1640 media supplemented with $10 \%$ FBS, $\beta$-mercaptoethanol, penicillin and streptomycin. Derivative melanoma cell lines expressing Nano luciferase under the control of the NF-kB response elements were generated by stable transfection of the parental cells with pNL3.2 NF-kBRE [NlucP NF-kB-RE Hygro] (Promega, Madison, WI). Primary human melanocytes were kindly provided by Dr. Z. Abdel-Malek (University of Cincinnati, Cincinnati, $\mathrm{OH})$ and cultured in Epilife culture media with TPA-free supplements (Thermo/Fisher, Grand Island, NY).

\section{Reagents}

Ladarixin, a dual CXCR1 and CXCR2 inhibitor was provided by Dompé Farmaceutici SpA, Via Campo di Pile, L'Aquila, Italy. LDX was prepared fresh daily by dissolving in culture media (in vitro experiments) or in PBS (in vivo experiments) to desired concentration.

\section{Analysis of chemokines secretion}

Chemokine-targeted antibody-based array (Ray Biotech, Norcross, GA) was used for analysis of melanocytic cell-derived secreted chemokines as devised by the manufacturer. Normalization and quantitation of chemokine secretion was done using array-specific Ray Biotech Analysis Tool.

\section{FACS}

Fluorescently-labeled CXCR1 and CXCR2-specific antibodies for FACS were from BioLegend (San Diego, CA). Cell sorting was done on Guava EasyCyte system and analyzed using InSyte Software (Millipore, Billerica MA).

\section{In vitro migration assay}

Cells were plated at sub-confluent density onto 6-well plates and grown to confluence. Then, a $0.5 \mathrm{~mm}$ scratch was introduced and cells were allowed to migrate into the area for $24 \mathrm{~h}$ in the presence or absence of LDX $\left(1 \times 10^{-5} \mathrm{M}\right)$. Ten independent images were taken from each cell line/condition and cells migrated into the scratch, were enumerated.

\section{Melanoma cell adhesion and attachment}

Different melanoma cells were plated onto 96 well plates and allow attaching to plastic substrata for 1, 2, 3 and $4 \mathrm{~h}$ or kept up to 5 days in the presence or absence of LDX $\left(1 \times 10^{-5} \mathrm{M}\right)$ in culture media. At indicated time points, cells were fixed in 3\% formaldehyde and stained with $0.1 \%$ crystal violet. After washes, plates were scanned at $570 \mathrm{~nm}$ on Bio Tech FL600 plate reader (Biotech Inc., Richmond, VA). Results were obtained from three independent experiments, three wells for each experiment.

\section{Assessment of apoptosis}

Apoptosis was assessed using In Situ Cell Death detection kit (TUNEL assay) (Roche Bioscience, 
Indianapolis, IN). Quantitation was done on images of 5 random microscopic fields per cell line per treatment.

\section{Treatment with LDX in vitro and in vivo}

For all in vitro experiments, unless otherwise stated, LDX was dissolved in phosphate buffered saline (PBS), filter-sterilized and used at $1 \times 10^{-5} \mathrm{M}$. For in vivo treatment of tumor-bearing animals, LDX was dissolved in PBS, filter-sterilized and used at $15 \mathrm{mg} / \mathrm{kg}$. LDX was administered via intraperitoneal (IP) injection once a day, every day, for the duration of the experiment. The dose was abopted from prior experiments on the $1^{\text {st }}$ generation of CXCR1 inhibitor, Reparixin [40]

\section{Animal treatment}

Eight cohorts of NCrNU-M nude spontaneous mutant standard athymic mice (Taconic, Hudson, NY) ( $n$ $=10$ per cohort) were intradermally injected with $1 \times 10^{6}$ melanoma cells (WM164, C8161, UM001, UM004) into right flanks in $30 \mu \mathrm{l}$ of saline. Lesions were pre-established for 10 days. Then, experimental animal were treated via IP injection of $100 \mathrm{l}$ of LDX in saline at $15 \mathrm{mg} / \mathrm{kg}$ dose, whereas 3 cohorts of control mice received saline. Dose and rout of administration were adopted from prior in vivo studies with first generation CXCR1 inhibitor, Reparixin [40].

\section{Tumor measurements}

Progression of the intradermal lesions was monitored by measuring 3 longest diameters using digital calipers. Tumor volume was calculated by multiplication of width $\mathrm{x}$ length $\mathrm{x}$ height.

\section{Indirect immunofluorescent and Western blot analyses}

Indirect immunofluorescent detection of antigens was done on paraformaldehyde fixed, Triton X-100 permeabilized $7 \mu \mathrm{m}$ cryo-sections or on cells plated onto glass chamber slides (Millipore, Billerica, MA) according to standard protocol. After permeabilization, slides were washed in PBS, blocked with $1 \%$ BSA and incubated with primary and secondary antibodies for $1 \mathrm{~h}$ each following counterstaining of nuclei with DAPI (Sigma, St. Louis, MO). Species-specific AlexaFluor ${ }^{488}$ - or AlexaFluor ${ }^{594}$ labeled secondary antibodies were from Thermo-Fisher (Thermo/Fisher, Grand Island, NY). Western blot analysis was done using cell and tumor lysates in RIPA buffer. All antibodies were used in recommended dilutions (provided in Supplementary Materials and Methods).

\section{Quantitation of microvessel density (MVD)}

Individual sections of LDX-treated and untreated tumor lesions were stained with CD31-specific antibodies (Thermo/Fisher, Grand Island, NY). Microvessel density was determined on ten random hotspots by direct counting of CD31-positive blood vessels as described previously [41]. Percent inhibition Thermo/Fisher, Grand Island, NY between MVD of untreated and treated lesions. MVD was assessed in control and LDX-treated lesions of a compatible size.

\section{RT-PCR}

Total RNA was isolated from cultured melanoma cells using RNeasy total RNA extraction kit (Qiagen, Valencia, CA). First-strand DNA was synthesized using Super Script III reverse transcriptase (Invitrogen, Grand Island, NY). Chemokines and receptors were amplified using the following primers: CXCL1 forward 5'- AGGGAATTCACCCCAAGAAC-3' and reverse 5'- TGGATTTGTCACTGTTCAGCA -3'; CXCL8 forward 5'-ATGACTTCCAAGCTGGCC-3' and reverse 5'-CAGACAGAGCTCTCTTCC-3'; CXCR1 forward 5'AGGGGCCACACCAACCTTCTG -3' and reverse 5'AGTGCCTGCCTCAATGTCTCCA 3'; CXCR2 forward 5'- CAGTTACAGCTCTACCCTGCC -3' and reverse 5'-CCAGGAGCAAGGACAGACCCC- 3'. Amplification of $\beta$-Actin was used as a loading control.

\section{Quantitation of immunostainings}

To quantify cells detected in lesions by the indirect immunofluorescence, 5 consecutive $7 \mu \mathrm{m}$ cryosections were taken from individual samples with 100 $\mu \mathrm{m}$ intervals. All generated sections were stained with respective antibodies and images of 3 random microscopic fields were taken. Fluorescent antibody-labeled cells were quantified on images using ImagePro software. Data for each antigen was averaged and standard deviations were determined.

\section{Statistical analysis}

Comparison of two samples (control vs treatment) was done using paired 2-tailed $t$-test. In tumor growth experiments, difference between LDX-treated and control tumors was considered statistically significant when significant difference was observed at 3 consecutive time points. $p<0.05$ was considered statistically significant. 


\section{Abbreviations}

LDX, Ladarixin; AKT, Protein kinase B; NF$\mathrm{kB}$, nuclear factor kappa B; STAT3, Signal transducer and activator of transcription 3;ALDH, Aldehyde dehydrogenases; TAM, Tumor-infiltrating macrophage; iNOS, inducible Nitric oxide synthases; PBS, Phosphate buffered saline; IP, intraperitoneal; MVD, microvessel density.

\section{ACKNOWLEDGMENTS}

We thank Drs. M. Herlyn and Z. Abdel-Malek for providing primary melanoma and melanocyte cell lines. This research was supported in part by: Melanoma Research Foundation grant for VA, American Dermatological Association scholarships for DMK and ML, Melanoma Research Foundation medical student grant for RJ.

\section{CONFLICTS OF INTEREST}

Authors declare no conflict of interest in relation to the work described in this manuscript.

\section{Authors contributions}

DMK conducted independent in vitro assessemnt of LDX activity on melanoma cell lines, analysis of LDX-treated tumor lesions and took part in manuscript preparation and editing; AP conducted initial assessment of LDX activity on cutaneous melanoma cell lines in vitro and was involved in manuscript preparation; ML and RJ were involved in animal studies and preparation of the manuscript; EL provided technical support to all studies and took part in the analysis of tumor lesions and manuscript preparation; TS provided access to uveal melanoma cell lines and was involved in discussion of results as well as prepartion of the manuscript; MT was involved in generation and characterisation of the primary uveal meanoma cell lines and analysis of LDX activity on these lines; MP coordinated the studies and was involved in manuscrpt writing and preparation; MA was involved in disign, development and testing of LDX in vitro; OI was involved in the analysis of tumor tissues and manuscript preparation and editing; VA conceived the idea for the project and was involved in all experiments, writing and preparation of the manuscript.

\section{Editorial note}

This paper has been accepted based in part on peerreview conducted by another journal and the authors' response and revisions as well as expedited peer-review in Oncotarget.

\section{REFERENCES}

1. Richmond A, Yang J and Su Y. The good and the bad of chemokines/chemokine receptors in melanoma. Pigment cell \& melanoma research. 2009; 22(2):175-186.

2. Balentien E, Mufson BE, Shattuck RL, Derynck R and Richmond A. Effects of MGSA/GRO alpha on melanocyte transformation. Oncogene. 1991; 6(7):1115-1124.

3. Haghnegahdar H, Du J, Wang D, Strieter RM, Burdick MD, Nanney LB, Cardwell N, Luan J, Shattuck-Brandt R and Richmond A. The tumorigenic and angiogenic effects of MGSA/GRO proteins in melanoma. Journal of leukocyte biology. 2000; 67(1):53-62.

4. Owen JD, Strieter R, Burdick M, Haghnegahdar H, Nanney L, Shattuck-Brandt R and Richmond A. Enhanced tumorforming capacity for immortalized melanocytes expressing melanoma growth stimulatory activity/growth-regulated cytokine beta and gamma proteins. International journal of cancer Journal international du cancer. 1997; 73(1):94-103.

5. Caunt M, Hu L, Tang T, Brooks PC, Ibrahim S and Karpatkin S. Growth-regulated oncogene is pivotal in thrombin-induced angiogenesis. Cancer research. 2006; 66(8):4125-4132.

6. Dhawan P and Richmond A. Role of CXCL1 in tumorigenesis of melanoma. Journal of leukocyte biology. 2002; 72(1):9-18.

7. Yang $\mathrm{J}$ and Richmond A. Constitutive IkappaB kinase activity correlates with nuclear factor-kappaB activation in human melanoma cells. Cancer research. 2001; 61(12):4901-4909.

8. Holmes WE, Lee J, Kuang WJ, Rice GC and Wood WI. Structure and functional expression of a human interleukin-8 receptor. Science. 1991; 253(5025):12781280 .

9. Moser B and Loetscher P. Lymphocyte traffic control by chemokines. Nature immunology. 2001; 2(2):123-128.

10. Brat DJ, Bellail AC and Van Meir EG. The role of interleukin- 8 and its receptors in gliomagenesis and tumoral angiogenesis. Neuro-oncology. 2005; 7(2):122-133.

11. Sharma B, Singh S, Varney ML and Singh RK. Targeting CXCR1/CXCR2 receptor antagonism in malignant melanoma. Expert opinion on therapeutic targets. 2010; 14(4):435-442.

12. Kaur $M$ and Singh D. Neutrophil chemotaxis caused by chronic obstructive pulmonary disease alveolar macrophages: the role of CXCL8 and the receptors CXCR1/ CXCR2. The Journal of pharmacology and experimental therapeutics. 2013; 347(1):173-180.

13. Garau A, Bertini R, Mosca M, Bizzarri C, Anacardio R, Triulzi S, Allegretti M, Ghezzi P and Villa P. Development of a systemically-active dual CXCR1/CXCR2 allosteric inhibitor and its efficacy in a model of transient cerebral 
ischemia in the rat. European cytokine network. 2006; 17(1):35-41.

14. Schaider $H$, Oka $M$, Bogenrieder $T$, Nesbit $M$, Satyamoorthy K, Berking C, Matsushima K and Herlyn M. Differential response of primary and metastatic melanomas to neutrophils attracted by IL-8. International journal of cancer Journal international du cancer. 2003; 103(3):335343.

15. Herlyn D, Iliopoulos D, Jensen PJ, Parmiter A, Baird J, Hotta H, Adachi K, Ross AH, Jambrosic J, Koprowski H and Herlyn M. In vitro properties of human melanoma cells metastatic in nude mice. Cancer research. 1990; 50(8):22962302.

16. Yu X, Ambrosini G, Roszik J, Eterovic AK, Stempke-Hale K, Seftor EA, Chattopadhyay C, Grimm E, Carvajal RD, Hendrix MJ, Hodi FS, Schwartz GK and Woodman SE. Genetic analysis of the 'uveal melanoma' C918 cell line reveals atypical BRAF and common KRAS mutations and single tandem repeat profile identical to the cutaneous melanoma C8161 cell line. Pigment cell \& melanoma research. 2015; 28(3):357-359.

17. Ozaki S, Vuyyuru R, Kageyama K, Terai M, Ohara M, Cheng H, Manser T, Mastrangelo MJ, Aplin AE and Sato T. Establishment and Characterization of Orthotopic Mouse Models for Human Uveal Melanoma Hepatic Colonization. The American journal of pathology. 2016; 186(1):43-56.

18. Igoucheva O, Kelly A, Uitto J and Alexeev V. Protein therapeutics for junctional epidermolysis bullosa: incorporation of recombinant beta3 chain into laminin 332 in beta3-/- keratinocytes in vitro. The Journal of investigative dermatology. 2008; 128(6):1476-1486.

19. Smythe WR, Williams JP, Wheelock MJ, Johnson KR, Kaiser LR and Albelda SM. Cadherin and catenin expression in normal human bronchial epithelium and nonsmall cell lung cancer. Lung Cancer. 1999; 24(3):157-168.

20. Williams HK, Sanders DS, Jankowski JA, Landini G and Brown AM. Expression of cadherins and catenins in oral epithelial dysplasia and squamous cell carcinoma. Journal of oral pathology \& medicine. 1998; 27(7):308-317.

21. Sizemore N, Leung $\mathrm{S}$ and Stark GR. Activation of phosphatidylinositol 3-kinase in response to interleukin-1 leads to phosphorylation and activation of the NF-kappaB p65/RelA subunit. Molecular and cellular biology. 1999; 19(7):4798-4805.

22. Kortylewski M, Jove R and Yu H. Targeting STAT3 affects melanoma on multiple fronts. Cancer metastasis reviews. 2005; 24(2):315-327.

23. de la Iglesia N, Konopka G, Lim KL, Nutt CL, Bromberg JF, Frank DA, Mischel PS, Louis DN and Bonni A. Deregulation of a STAT3-interleukin 8 signaling pathway promotes human glioblastoma cell proliferation and invasiveness. The Journal of neuroscience. 2008; 28(23):5870-5878.

24. Edin S, Wikberg ML, Dahlin AM, Rutegard J, Oberg
A, Oldenborg PA and Palmqvist R. The distribution of macrophages with a M1 or M2 phenotype in relation to prognosis and the molecular characteristics of colorectal cancer. PloS one. 2012; 7(10):e47045.

25. Varney ML, Johansson SL and Singh RK. Distinct expression of CXCL8 and its receptors CXCR1 and CXCR2 and their association with vessel density and aggressiveness in malignant melanoma. American journal of clinical pathology. 2006; 125(2):209-216.

26. Boonyaratanakornkit JB, Yue L, Strachan LR, Scalapino KJ, LeBoit PE, Lu Y, Leong SP, Smith JE and Ghadially R. Selection of tumorigenic melanoma cells using ALDH. The Journal of investigative dermatology. 2010; 130(12):27992808.

27. Luo Y, Dallaglio K, Chen Y, Robinson WA, Robinson SE, McCarter MD, Wang J, Gonzalez R, Thompson DC, Norris DA, Roop DR, Vasiliou V and Fujita M. ALDH1A isozymes are markers of human melanoma stem cells and potential therapeutic targets. Stem Cells. 2012; 30(10):2100-2113.

28. Chen L, Fan J, Chen H, Meng Z, Chen Z, Wang P and Liu L. The IL-8/CXCR1 axis is associated with cancer stem cell-like properties and correlates with clinical prognosis in human pancreatic cancer cases. Scientific reports. 2014; 4:5911.

29. Ginestier C, Liu S, Diebel ME, Korkaya H, Luo M, Brown M, Wicinski J, Cabaud O, Charafe-Jauffret E, Birnbaum D, Guan JL, Dontu G and Wicha MS. CXCR1 blockade selectively targets human breast cancer stem cells in vitro and in xenografts. The Journal of clinical investigation. 2010; 120(2):485-497.

30. Gordon JR, Li F, Zhang X, Wang W, Zhao X and Nayyar A. The combined CXCR1/CXCR2 antagonist CXCL8(374)K11R/G31P blocks neutrophil infiltration, pyrexia, and pulmonary vascular pathology in endotoxemic animals. Journal of leukocyte biology. 2005; 78(6):1265-1272.

31. Schneberger D, Gordon JR, DeVasure JM, Boten JA, Heires AJ, Romberger DJ and Wyatt TA. CXCR1/ CXCR2 antagonist CXCL8(3-74)K11R/G31P blocks lung inflammation in swine barn dust-instilled mice. Pulmonary pharmacology \& therapeutics. 2015; 31:55-62.

32. Singh S, Sadanandam A, Nannuru KC, Varney ML, MayerEzell R, Bond R and Singh RK. Small-molecule antagonists for CXCR2 and CXCR1 inhibit human melanoma growth by decreasing tumor cell proliferation, survival, and angiogenesis. Clin Cancer Res. 2009; 15(7):2380-2386.

33. Gonsiorek W, Fan X, Hesk D, Fossetta J, Qiu H, Jakway J, Billah M, Dwyer M, Chao J, Deno G, Taveras A, Lundell DJ and Hipkin RW. Pharmacological characterization of Sch527123, a potent allosteric CXCR1/CXCR2 antagonist. The Journal of pharmacology and experimental therapeutics. 2007; 322(2):477-485.

34. Chapman RW, Minnicozzi M, Celly CS, Phillips JE, Kung TT, Hipkin RW, Fan X, Rindgen D, Deno G, Bond R, Gonsiorek W, Billah MM, Fine JS and Hey JA. A novel, 
orally active CXCR1/2 receptor antagonist, Sch527123, inhibits neutrophil recruitment, mucus production, and goblet cell hyperplasia in animal models of pulmonary inflammation. The Journal of pharmacology and experimental therapeutics. 2007; 322(2):486-493.

35. Holz O, Khalilieh S, Ludwig-Sengpiel A, Watz H, Stryszak P, Soni P, Tsai M, Sadeh J and Magnussen H. SCH527123, a novel CXCR2 antagonist, inhibits ozone-induced neutrophilia in healthy subjects. The European respiratory journal. 2010; 35(3):564-570.

36. Nair KK, Pillai HS, Thajudeen A, Tharakan J, Titus T, Valaparambil A, Sivasubramonian S, Mahadevan KK, Namboodiri N, Sasidharan B and Ganapathi S. Comparative study on safety, efficacy, and midterm results of balloon mitral valvotomy performed with triple lumen and double lumen mitral valvotomy catheters. Catheterization and cardiovascular interventions. 2012; 80(6):978-986.

37. Nair P, Gaga M, Zervas E, Alagha K, Hargreave FE, O'Byrne PM, Stryszak P, Gann L, Sadeh J and Chanez P. Safety and efficacy of a CXCR2 antagonist in patients with severe asthma and sputum neutrophils: a randomized, placebo-controlled clinical trial. Clinical and experimental allergy. 2012; 42(7):1097-1103.
38. Bertini R, Barcelos LS, Beccari AR, Cavalieri B, Moriconi A, Bizzarri C, Di Benedetto P, Di Giacinto C, Gloaguen I, Galliera E, Corsi MM, Russo RC, Andrade $\mathrm{SP}$, et al. Receptor binding mode and pharmacological characterization of a potent and selective dual CXCR1/ CXCR2 non-competitive allosteric inhibitor. British journal of pharmacology. 2012; 165(2):436-454.

39. Hattermann K, Holzenburg E, Hans F, Lucius R, HeldFeindt $\mathrm{J}$ and Mentlein R. Effects of the chemokine CXCL12 and combined internalization of its receptors CXCR4 and CXCR7 in human MCF-7 breast cancer cells. Cell and tissue research. 2014; 357(1):253-266.

40. Villa P, Triulzi S, Cavalieri B, Di Bitondo R, Bertini R, Barbera S, Bigini P, Mennini T, Gelosa P, Tremoli E, Sironi $\mathrm{L}$ and Ghezzi P. The interleukin-8 (IL-8/CXCL8) receptor inhibitor reparixin improves neurological deficits and reduces long-term inflammation in permanent and transient cerebral ischemia in rats. Mol Med. 2007; 13(3-4):125-133.

41. Weidner N, Semple JP, Welch WR and Folkman J. Tumor angiogenesis and metastasis--correlation in invasive breast carcinoma. The New England journal of medicine. 1991; 324(1):1-8. 